\title{
The Application of User Portrait Based on Big Data Analysis in Industrial Design Teaching
}

\author{
Chen $\mathrm{Ni}^{1}$, Li Wang ${ }^{1}$ \\ ${ }^{1}$ School of Design \& Art, Dalian Institute of Science and Technology, Dalian, LiaoNing, 116052, China
}

\begin{abstract}
User analysis is increasingly important in today's design activities. Through data analysis platforms and user behavior analysis tools, students can efficiently and accurately summarize product positioning, core concepts, distinctive features, and other aspects of the early design stage, and use the data to grasp user characteristics more accurately. Eventually, the goal of cultivating students' user analysis ability is achieved, which plays an important role in the training of industrial design talents in the context of big data analysis and new retail.
\end{abstract}

\section{Background}

As an effective tool for sketching target users, connecting users' demands and design directions, user portrait has been widely used in various fields. User portrait was originally applied in the field of e-commerce. In the era of big data, user information is flooded in the network. We can abstract each user' $s$ specific information into tags, and use these tags to embody the user's image, so as to provide users with targeted services [1].

In the current industrial design process, there are so many participants in each link that differences are inevitable. The efficiency of decision-making undoubtedly affects the progress of the project. User portrait comes from the research on target users. When all people involved in the product discuss and make decisions based on the same users, it is easy to restrict all parties to stay in the same direction and improve the efficiency of decision-making. Looking at successful product and service design cases, the target users they serve are usually very clear and distinctive, their products pursue excellence with the utmost attention, and they are able to solve core problems. Products based on the new retail context, such as Fresh Hema and Tsutaya Books, have always served maverick people with attitudes, and pursuit of quality, winning a good reputation and market share. Therefore, providing focused services to specific groups is far closer to success than providing low-standard services to a wide range of people.

Emphasizing user analysis in design teaching can to some extent prevent students from representing users rashly in the subject. Replacing users 'voices is a common phenomenon in industrial design. Students often unconsciously assume that users' expectations are in line with their own, and they are always under the banner of "serving users". The result is that users often don't approve of our well-designed service, or even think it's terrible.

\section{Challenges of Data Analysis Tools to Existing Design Teaching Methods}

Product planning and concept determination are often the core stages of a design project. The main task at this stage is to know and analyze users. [2] In the context of big data analysis and new retail, the methods of user analysis in teaching also change with the creation of these new tools and resources.

\subsection{Outdated Information Sources are Out of Touch with Design Practices}

In traditional design teaching, the preliminary demonstration of a design project is usually conducted only through user survey questionnaires and user interviews. This method tends to be more one-sided. To reflect user characteristics objectively, it often takes a long time to collect a large amount of information to reach the corresponding sample number, and there is no corresponding class time and cycle to complete such projects in daily teaching. Therefore, the existing teaching content cannot meet the needs of user analysis in the context of big data analysis, and students cannot master the use of data analysis tools.

\subsection{Challenges of User Portraits Based on Big Data Analysis to Traditional Teaching Methods}

Nowadays, more and more design companies use data analysis tools to know their users. However, in the existing design teaching, teachers still use traditional needs surveys and related product surveys to carry out

* Corresponding author: E-mail: nichen93@hotmail.com 
preliminary work (see Figure 2-1) and rarely guide

students to use rich data resources. [3]

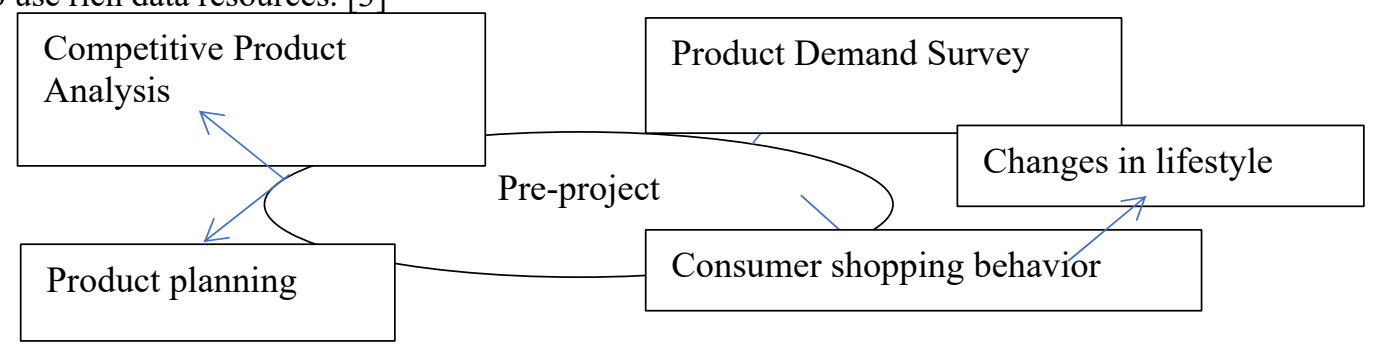

Figure 1. The basic composition of the preliminary work of the design project

There are various methods of collecting information used in the early stage of design. The key is to choose the method that can achieve the goal. The basic starting point is to find important demand changes and their commercialization. Therefore, we can use data analysis platforms and user behavior analysis tools to enable students to efficiently and accurately summarize the product positioning, core concepts, distinctive features, and other aspects of the early design stage, and grasp user characteristics more accurately through the data.

\section{The Core Meaning of User Portrait Based on Big Data Analysis to Design Teaching}

The use of analysis tools for user portrait based on big data analysis in teaching is designed to enable students to quickly summarize behavior characteristics of target population through data analysis methods, and to develop the product that meets the corresponding needs, making it an important tool for user research, thereby cultivating students' ability to learn and explore knowledge independently. Various data platforms can collect a large amount of user information and usage records. When students face these data, they may have a feeling of blindness and inability to start, which requires teachers to change teaching methods and guide students to summarize user habits and related characteristics through data. In this way, students can change from passive learners to active researchers, and teachers mainly play the role of solving difficult problems, answering questions, and deepening knowledge. The role of teachers has also changed from the traditional lecturers to class designers, mentors, and collaborators, and the interaction with students has been greatly enhanced.

Through detailed demonstration, we conclude that the teaching reform has the following four core meanings:

- With the teaching reform of design theory course carried out, new teaching methods explored and new training models studied, this stage mainly completes the application of user portraits through data analysis in design theory courses.

- Analyze user characteristics of specific products in combination with enterprise data platforms and master relevant analysis methods.

- Carry out research on student innovation and entrepreneurship projects, set up multiple student entrepreneurship teams, and study user analysis mechanisms and accumulate experience through practice.

- Taking the annual college graduation design exhibition as an opportunity, invite industry experts, enterprises and institutions to participate, expanding students' foreign exchange platforms.

\section{Practice of User Portraits Based on Big Data Analysis in Industrial Design Teaching}

User analysis ability is the core ability for the training of industrial design professionals. The corresponding professional courses include "Design Procedures and Methods", "Design Psychology", "Business Operation and Design Strategy", etc. Fast and accurate analysis of the eight PERSONAL elements of user portraits through big data analysis methods can equip students with solid practical skills and corresponding design theory, which is of great significance to the achievement of the course objectives. [4] In the context of the post-Internet era, with the rapid development of technology, the role of user characteristics in the entire product design process has become increasingly important. Therefore, we combine the user analysis process based on professional data analysis platforms in the design industry to form a new user analysis ability training process, (Figure 4-1) actively explore new models of design teaching in the post-Internet era, thereby improving the quality of professional teaching. 


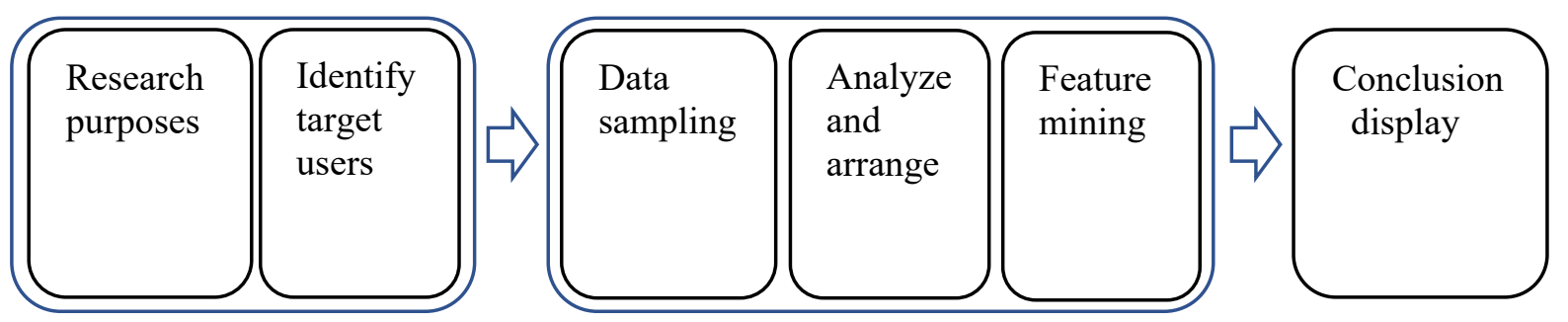

Figure 2. User analysis ability training flowchart

In the professional teaching, we follow the idea of "Project-based classroom teaching and Result-oriented course work" to realize the integration of curriculum and design practice. While acquiring the corresponding professional knowledge, students gain practical work experience with real project training and gradually grow from novices to innovative designers.

In the course teaching led by the development of user analysis ability, we have introduced a number of practical projects to achieve the goal of project-based classroom teaching, so that students can quickly integrate into the job after graduation, thereby achieving an effective link between school and enterprise. For example, we have introduced "improvement of user analysis and service design of a commodity chain supermarket" into professional teaching. When conducting customer analysis, in addition to guiding students to analyze normal data such as store sales, personal sales, monthly break-even point, we also obtained some key data from the supermarket's surveillance video analysis. The first is the percentage of

Table 1. User analysis of different supermarks. people who bought things in the store. We found that many people walked around in the mall and left without buying anything, so this ratio is the most important index of how well a mall is doing, indicating the number of people who come to your store and make purchases. The research shows that the conversion rate of this store is about $50 \%$. The second is the purchase time, which is how long it takes a customer to buy an item on average. It was found from the video that the customer's purchase time is about thirty seconds. Those who do not buy are generally nostalgic for about two minutes. The third is waiting time, which is the time required to buy an item. If the waiting time is too long, the consumer will not buy it. We found through video analysis that the main part of the customer's waiting in the store is the checkout. Each additional customer queue in front will increase the waiting time by about 1 minute on average. The fourth is the analysis of the average number of customer steps. We found that when customers step over 60 steps / minute, the purchase behavior will be greatly reduced.

\begin{tabular}{lccc}
\hline & Supermarket1 & Supermarket2 & Supermarket3 \\
\hline Purchase time & $42 \mathrm{~s}$ & $35 \mathrm{~s}$ & $44 \mathrm{~s}$ \\
Waiting time & $41 \mathrm{~s}$ & $37 \mathrm{~s}$ & $67 \mathrm{~s}$ \\
AVG. steps & 44 & 40 & 46 \\
Purchase percent & $48 \%$ & $56 \%$ & $45 \%$ \\
\hline
\end{tabular}

\section{Conclusion}

By comparing the data of several dimensions obtained through field research on the data platform, we can get a relatively objective store user portrait. Teachers then guide their students to draw a store improvement plan through the user portrait. For example, reduce the time for customers to make a purchase, so that people can buy what they want with greater efficiency; improve customers' checkout experience, and ensure good order even if they need to line up; extend the shopping environment by designing some discounted promotional shelves at the entrance of the store, which can reduce the area as much as possible while attracting customers' attention, thus effectively slowing down the pace of customers.

This change in teaching method intuitively displays the original abstract user analysis knowledge in front of students, enabling students to quickly integrate into the role of designers. Through clear and quantifiable methods, students' ability to find and solve problems can be gradually developed. [5] In professional teaching, we also have related successful teaching cases such as the improved design of ticket gates in rail transit stations, and the modularized improvement plan for shared bicycles. Through training, students can quickly and accurately locate the core concepts of the product, discuss and make decisions on all design elements based on consistent users, improving the efficiency of decision-making. It plays a very important role in cultivating students' user analysis ability.

\section{References}

1. J Garrett (2012) The Elements of User Experience. China Machine Press08:7-8.

2. Stevens H (2016) Big data, little data, no data: scholarship in the networked world by christine 1 . borgman (review). J Assoc Inf Sci Technol 67(3):256-257

3. Fishbein M, Ajzen I (1977) Belief, attitude, intention, and behavior: an introduction to theory 
and research. Contemp Sociol 6(2)

4. Ringle CM,Wende S, Becker JM (2015) Smart PLS

3. Boenningstedt: SmartPLS GmbH.Available

online at: Retrieved from UK. http://www.smartpls.com

5. Zhang haichao. (2015) A Discusison on the Level of Requirements and Design Strategies in Interactive Design. Art Science and Technology(11)288 